Research Article

\title{
An Efficient and Practical Method for the Synthesis of Saxagliptin Intermediate 2-(3-Hydroxy-1-adamantane)-2-oxoacetic Acid and Its Optimization
}

\author{
Qi Liao (iD, ${ }^{1}$ Lan Jiang, ${ }^{2}$ Cong Li, ${ }^{1}$ Yaling Shen, ${ }^{1}$ Min Wang, ${ }^{1}$ Chengkun Cao, ${ }^{1}$ \\ and Xiangnan $\mathrm{Hu} \mathbb{1}^{1}$ \\ ${ }^{1}$ Department of Medicinal Chemistry, Pharmacy School, Chongqing Medical University, Chongqing, China \\ ${ }^{2}$ College of Environment and Resources, Chongqing Technology and Business University, Chongqing, China \\ Correspondence should be addressed to Xiangnan Hu; huxiangnan@cqmu.edu.cn
}

Received 28 June 2019; Accepted 13 September 2019; Published 10 October 2019

Academic Editor: Gabriel Navarrete-Vazquez

Copyright (C) 2019 Qi Liao et al. This is an open access article distributed under the Creative Commons Attribution License, which permits unrestricted use, distribution, and reproduction in any medium, provided the original work is properly cited.

A mild and relatively simple way for preparation of 2-(3-hydroxy-1-adamantane)-2-oxoacetic acid (I) was reported. It was prepared from 1-adamantanecarboxylic acid (II) via sulfuric acid/nitric acid to get 3-hydroxy-1-adamantanecarboxylic acid (III); treated with the one-pot method through acylation, condensation, and decarboxylation to obtain 3-hydroxy-1-acetyladamantane (IV); and finally oxidized by potassium permanganate $\left(\mathrm{KMnO}_{4}\right)$ to get the target compound (I). The overall yield was about $60 \%$, which provides a new idea for commercial production of saxagliptin intermediate.

\section{Introduction}

Diabetes, a complex and chronic illness, is becoming a public health problem and even a global societal catastrophe. According to the figures displayed in the 8th edition of the Diabetes Atlas issued by the International Diabetes Federation, until 2017, there were about 451 million adults who lived with diabetes all over the world, and this number may rise to 693 million in 2045, if nothing is done [1].

Dipeptidyl peptidase-4 (DPP-4) inhibitors are classic antihyperglycemic agents used worldwide [2]. Up-to-date studies and analysis reveal clearly that the overall tolerance/ safety profile of DPP-4 inhibitors appears better than that of other oral glucose-lowering agents [3]. Compared with sulfonylureas etc., DPP-4 inhibitors may represent a costeffective option [4].

Saxagliptin (Onglyza) is a highly potent and selective DPP-4 inhibitor authorized by FDA in 2009 [5]. Due to its distinctive mechanism of action and a series of clinical trials, FDA approved its combination with metformin (Kombiglyze XR) and dapagliflozin (Qtern) in 2010 and 2017 [6].
Through retrosynthesis analysis, we found that (S)-NBoc-3-hydroxyadamantylglycine is a key intermediate of Saxagliptin [7], and it can be prepared economically and efficiently from 2-(3-hydroxy-1-adamantyl)-2-oxoacetic acid (I) by asymmetric reductive amination $[8,9]$ (Figure 1).

Not surprising, much effort has been made to synthesize this essential intermediate I (Figure 2). Politino et al. [10] originally describe a method treating 1-bromoadamantane as starting material, which reacted with silane coupling agent to give $\alpha$ hydroxy acid and then through esterification, Swern oxidation, hydroxylation, and hydrolysis to produce the target compound I. However, harsh reaction conditions involved in Swern oxidation $\left(-78^{\circ} \mathrm{C}\right)$ restrict the route for commercial manufacturing.

Henryon et al. [11] developed an improved route to start with 1-adamantanecarboxylic acid, which was acylated by thionyl chloride $\left(\mathrm{SOCl}_{2}\right)$ and substituted by cyanide reagent TMSCN to afford cyanide and then underwent hydrolysis, esterification, and hydroxylation to obtain the intermediate. But it was found that this route demanded greatly multiple procedures as well as relatively complex 


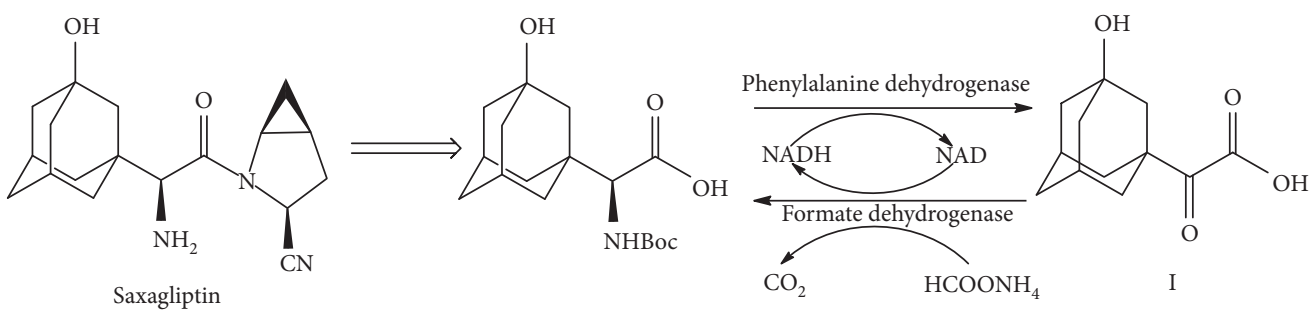

FIGURE 1: Retrosynthesis analysis of Saxagliptin.
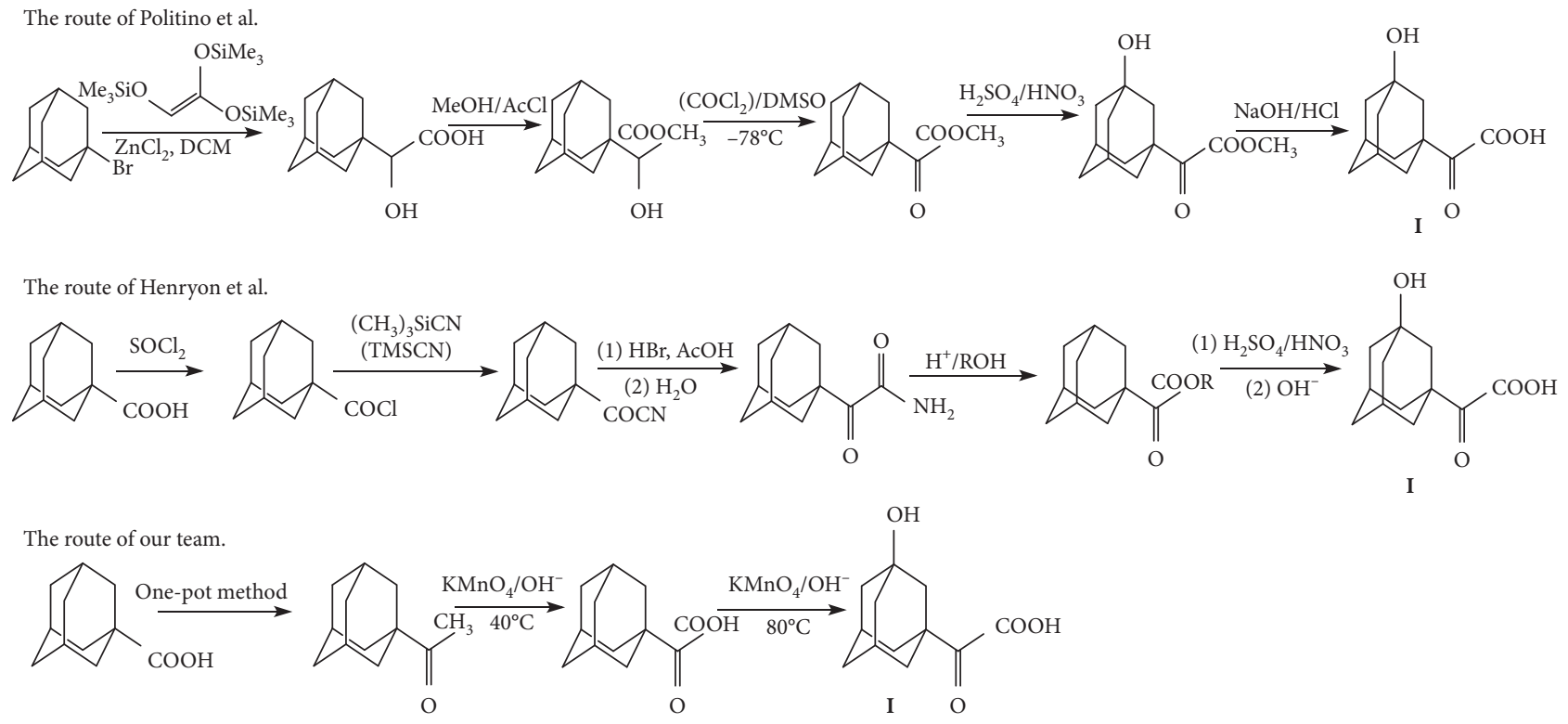

FIgURE 2: The existing methods to synthesize I.

operation. Furthermore, the overall yields were unsatisfactory (28\%) and thus were not adequate for implementation of a large-scale work.

Our team [12] reported a method to prepare the target compound. Regarded 1-adamantanecarboxylic acid as raw material which was methylated by the one-pot method to obtain 1-acetyladamantane and afterwards through oxidation and hydroxylation to acquire compound I. The scheme we came up with required inexpensively acceptable materials and mild reaction conditions. But the yield of hydroxylation is relatively low (68\%) which limited the application to industrial production.

In in-depth study, we found that the hydroxylation of adamantane tertiary carbon was the key factor affecting the total yield. A series of methods were reported, but the results were disappointed (Figure 3). Berner et al. [13], using 1acetyladamantane as the first material via one-step oxidation, introduced the hydroxyl and carboxyl group (36\%). Li et al.[12] used two-step oxidation and hydroxylation in the second step, but they did not get the good result(61\%). Wilhelm et al. [14] made 1-adamantane glycine as the raw material hydroxyl, but the yields are still low (66\%). Venkat et al. [15] protected the amino group; however, the hydroxylation yields lower (40\%). Bertolini et al. [16] kept hydroxylation as the last step of Saxagliptin synthesis, but the yields are still low (74\%).
To sum up, it seems to delay the hydroxylation step always to reduce the yield. Our team analyzed the reason for the low yield. We believe that the key to solve the problem should be on the adamantane ring. The nature of hydroxylation is adamantane oxidation. Due to the presence of electron-withdrawing substituents, electron-withdrawing effects may decrease the cloud density of the adamantane ring and cause difficulty in oxidation. On the other hand, the spatial effect may also increase steric hindrance, making it difficult for oxidants to fully react with raw materials and lead to low yields. Thus, if we change the oxidation sequence and advance the hydroxylation to avoid the above problems, it may be a feasible way to increase the yield.

\section{Results and Discussion}

On account of the above hypothesis, we made some improvements based on our laboratory previous work $[12,17,18]$ and developed an efficient and practical method for the synthesis of $\mathbf{I}$. The specific improvements of route are depicted in Figure 4:

It was prepared from 1-adamantanecarboxylic acid (II) via sulfuric acid/nitric acid to get 3-hydroxy-1-adamantanecarboxylic acid (III); treated with the one-pot method through acylation, condensation, and decarboxylation to obtain 3-hydroxy-1-acetyladamantane 


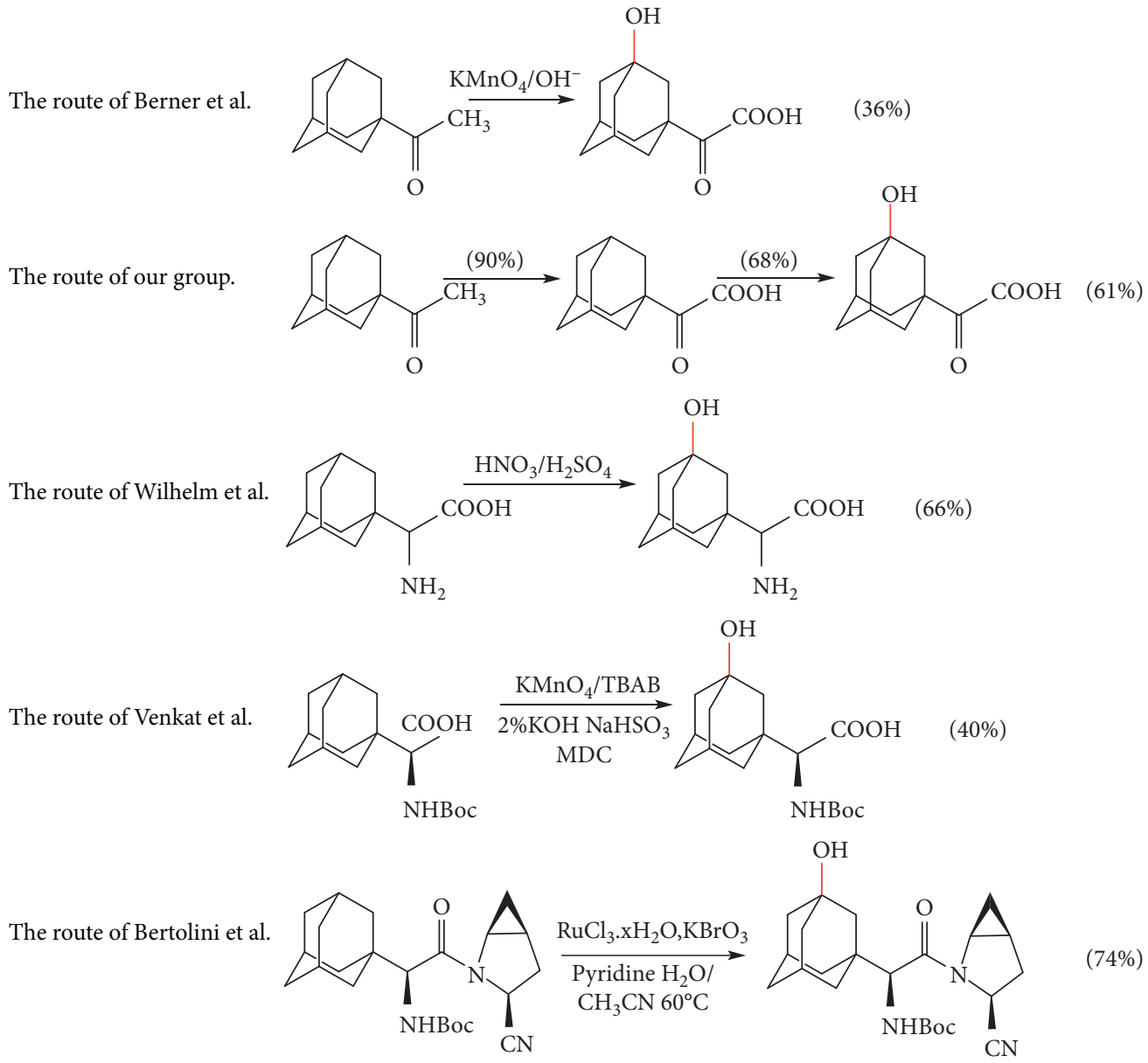

FIGURE 3: The existing methods to introduce the hydroxyl.

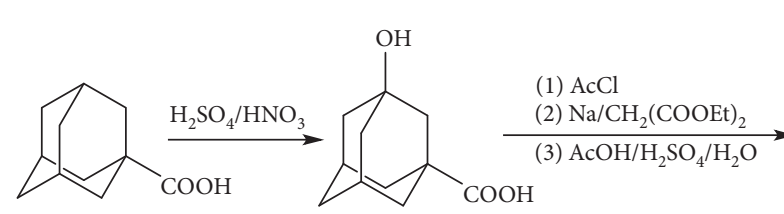

II

III

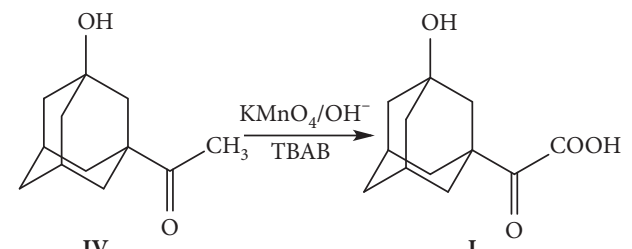

IV

Figure 4: A convenient approach to prepare I.

(IV); and finally oxidized by potassium permanganate $\left(\mathrm{KMnO}_{4}\right)$ to get the target compound (I).

In the process optimization, we focused on the synthesis of IV and I. In the one-pot method step synthesis of IV, we used acetyl chloride $\left(\mathrm{CH}_{3} \mathrm{COCl}\right)$ with lower activity instead of $\mathrm{SOCl}_{2}$, aiming to shorten the duration of reactions and improve production efficiency (Figure 5) because the latter also led to chlorination of 3-hydroxy to form the byproduct, which would increase our workload (Figure 6). In addition, we optimized the step of acylation reaction via central composite design-response surface methodology concentrate upon four vital factors after single factor experiment study of 3-hydroxy-1-acetyladamantane [19].

Furthermore, the species of catalyst used in the synthesis of I was screened, which represented a great improvement compared with our previous work that increased the reaction yield effectively. The optimized reaction conditions shortened the reaction time, saved cost, and gave the target compound with $60 \%$ yield, which was suitable for industrial production.

Central composite design-response surface methodology has been widely used for process optimization in recent years, which has the advantages of high precision and good predictability and being sensitive to examine the interaction between the various factors [20,21]. In the step of acylation reaction, it was used to summarize the key factors affecting the experiment, which optimized the experimental conditions and achieve a better result.

The factors influencing the yield of compound IV were as follows: the species of the catalyst (Table 1), the catalyst loading (Figure 7), the mole ratio of acetyl chloride to compound III (Figure 8), reaction temperature (Figure 9), 


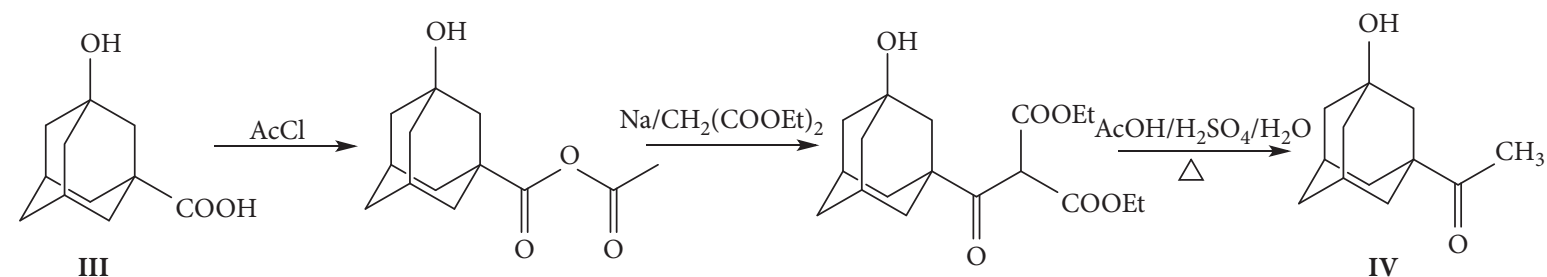

FIgURE 5: Improved one-pot method.

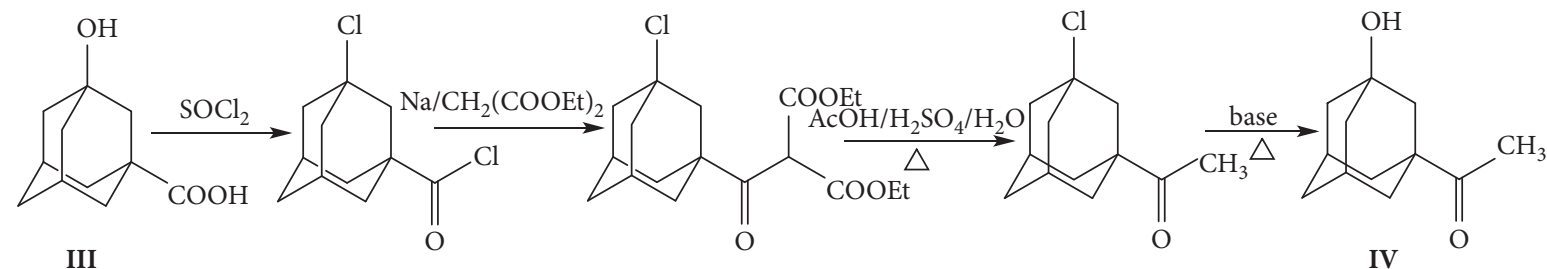

FIGURE 6: Initial one-pot method.

TABle 1: The impact of catalyst on yield.

\begin{tabular}{lcc}
\hline Catalyst & The feed ratios of the catalyst to raw materials (mol/ & The yield of compound IV (\%) \\
\hline Pyridine & 1.5 & 72.1 \\
DMAP & 1.5 & 65.3 \\
Triethylamine & 1.5 & 68.2 \\
DMF & 1.5 & 32.2 \\
- & - & 43.0 \\
\hline
\end{tabular}

and reaction time (Figure 10). Therefore, the five factors above were set to several levels in the pre-experiment and used single factor experiment study to investigate the effects of them on the yield of compound IV. The specific result is shown below.

After confirming the preliminary range of the variables via single-factor experiment, a central composite designresponse surface methodology with four independent factors $\left(X_{\mathrm{a}}\right.$, molar ratio of acetyl chloride to compound 3; $X_{\mathrm{b}}$, reaction time; $X_{\mathrm{c}}$, reaction temperature; and $X_{\mathrm{d}}$, the pyridine loading) at five levels was performed. For statistical calculation, the levels were coded as $-2,-1,0,+1$, and +2 , respectively, in which -2 corresponds to the low level of each factor, +2 to the high level, and 0 to the midlevel. The result of central composite design-response surface methodology is described in Table 2. As seen from Table 2, the complete design consisted of 30 experimental points, and the experiment was carried out in a random order. Each factor has been implemented multiple linear regression and binomial fitting via the software of DesignExpert 8.0.6 [18].

Multiple linear regression equation was

$$
\begin{aligned}
R(\text { yield })= & R_{1}=+60.31767+1.13750 X_{\mathrm{a}}-0.53917 X_{\mathrm{b}} \\
& +0.90417 X_{\mathrm{c}}+0.82083 X_{\mathrm{d}}, \quad r_{1}=0.20 .
\end{aligned}
$$

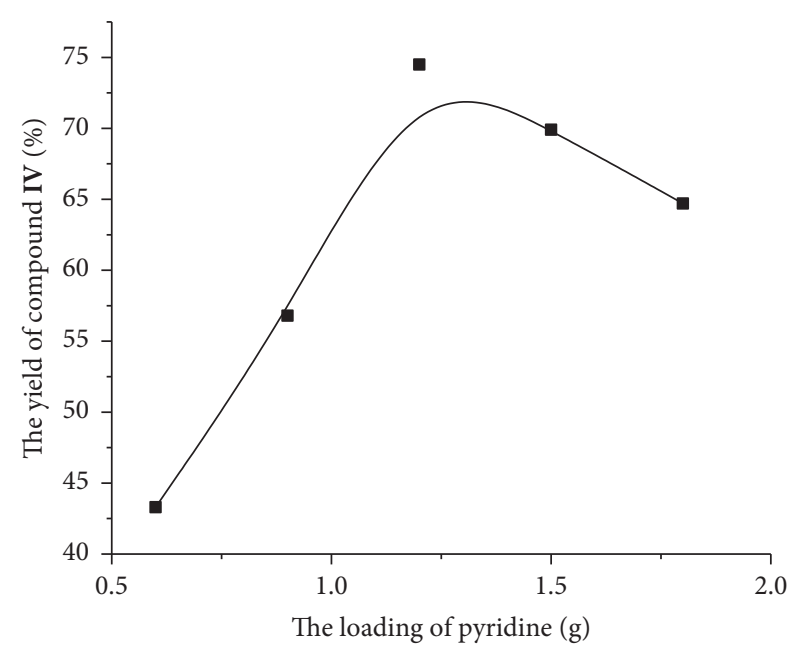

Figure 7: Impact of catalyst loading.

$$
\begin{aligned}
R(\text { yield })= & R_{2}=+73.39167+1.13750 X_{\mathrm{a}}-0.53917 X_{\mathrm{b}} \\
& +0.90417 X_{\mathrm{c}}+0.82083 X_{\mathrm{d}}+0.39625 X_{\mathrm{a}} X_{\mathrm{b}} \\
& +0.73625 X_{\mathrm{a}} X_{\mathrm{c}}+0.36125 X_{\mathrm{a}} X_{\mathrm{d}}-0.30375 X_{\mathrm{b}} X_{\mathrm{c}} \\
& -1.02875 X_{\mathrm{b}} X_{\mathrm{d}} \\
& -1.03875 X_{\mathrm{c}} X_{\mathrm{d}}-3.879372 X_{\mathrm{a} 2}-3.12938 X_{\mathrm{b} 2} \\
& -5.10437 X_{\mathrm{c} 2}-4.229 X_{\mathrm{d} 2}, \quad r_{2}=0.91 .
\end{aligned}
$$

The binomial equation was 


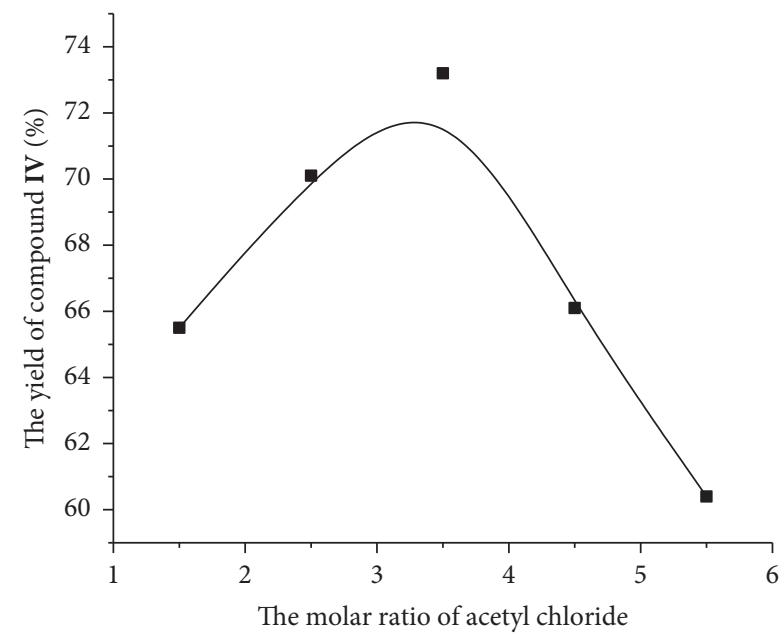

Figure 8: Impact of mole ratio of acetyl chloride.

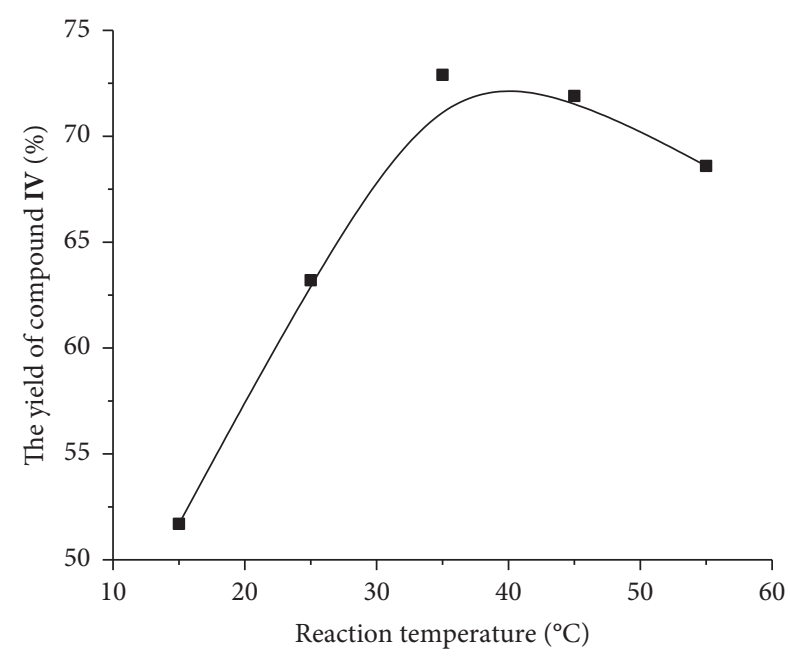

FIgURE 9: Impact of reaction temperature.

From the equation above, the correlation coefficient of binomial equation $\left(r_{2}\right)$ was bigger than multiple linear regression $\left(r_{1}\right)$ which means the actual values were well in close agreement with the predicted values, so we chose that the binomial model was the better one ultimately.

According to the obtained binomial equation, the corresponding 3-D response surface plot of compound IV is depicted in Figure 11. As shown in Figure 11, within limits, the yield rose as the molar ratio of acetyl chloride to compound III rose, reaction time prolonged, reaction temperature increased, and the pyridine loading enhanced and then reached the maximum value, but beyond a certain level, the yield decreased. Each response surface has its optimal interval, and higher yields could be obtained when the reaction conditions were in the region, via overlapped the optimal region of each response surface, optimized range of producing compound 6 was obtained as shown below: $X_{\mathrm{a}}$ : 2.9 : 1 3.4: $1 ; X_{\mathrm{b}}: 3 \sim 4 \mathrm{~h} ; X_{\mathrm{c}}: 30 \sim 55^{\circ} \mathrm{C}$; and $X_{\mathrm{d}}: 1.4 \sim 1.6 \mathrm{~g}$.

However, with a view to operation of the process and input-output ratio, the final reaction conditions we selected among the above ranges were: The molar ratio of acetyl

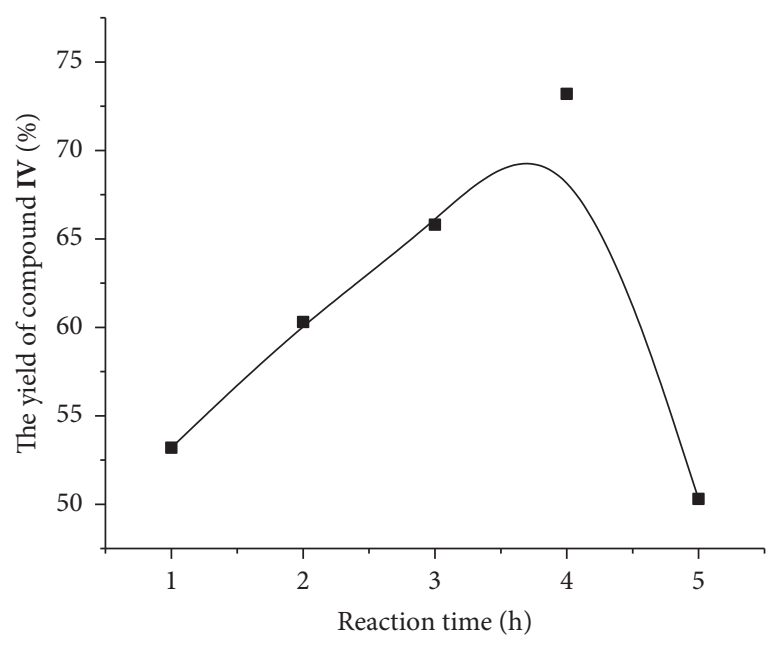

FIGURE 10: Impact of reaction time.

TABLE 2: The results of central composite design-response surface methodology.

\begin{tabular}{|c|c|c|c|c|c|}
\hline Number & $\begin{array}{c}X_{\mathrm{a}} \\
(\mathrm{mol} / \mathrm{mol})\end{array}$ & $X_{\mathrm{b}}(\mathrm{h})$ & $X_{c}\left({ }^{\circ} \mathrm{C}\right)$ & $X_{\mathrm{d}}(\mathrm{g})$ & $\begin{array}{c}\text { Actual yield } \\
(\%)\end{array}$ \\
\hline 1 & 0 & 0 & 0 & 2 & 53.3 \\
\hline 2 & 2 & 0 & 0 & 0 & 56.9 \\
\hline 3 & 0 & -2 & 0 & 0 & 58.9 \\
\hline 4 & 0 & 0 & 2 & 0 & 50.5 \\
\hline 5 & 1 & -1 & 1 & 1 & 63.22 \\
\hline 6 & -1 & -1 & 1 & 1 & 60.7 \\
\hline 7 & 0 & 0 & 0 & -2 & 50.3 \\
\hline 8 & 0 & 0 & 0 & 0 & 72.6 \\
\hline 9 & -1 & 1 & -1 & 1 & 60.3 \\
\hline 10 & -1 & -1 & 1 & -1 & 55 \\
\hline 11 & -1 & -1 & -1 & -1 & 56.44 \\
\hline 12 & 1 & -1 & -1 & -1 & 55.5 \\
\hline 13 & 1 & 1 & 1 & -1 & 62.7 \\
\hline 14 & -2 & 0 & 0 & 0 & 49.5 \\
\hline 15 & 1 & 1 & -1 & 1 & 59.9 \\
\hline 16 & 0 & 0 & -2 & 0 & 46.1 \\
\hline 17 & -1 & -1 & -1 & 1 & 60.5 \\
\hline 18 & 0 & 0 & 0 & 0 & 73.45 \\
\hline 19 & 1 & 1 & 1 & 1 & 61.22 \\
\hline 20 & 0 & 2 & 0 & 0 & 53.5 \\
\hline 21 & 1 & 1 & -1 & -1 & 57.9 \\
\hline 22 & 0 & 0 & 0 & 0 & 74.7 \\
\hline 23 & -1 & 1 & 1 & -1 & 60.2 \\
\hline 24 & 0 & 0 & 0 & 0 & 75.8 \\
\hline 25 & 0 & 0 & 0 & 0 & 73.9 \\
\hline 26 & 0 & 0 & 0 & 0 & 69.9 \\
\hline 27 & 1 & -1 & 1 & -1 & 59.7 \\
\hline 28 & 1 & -1 & 1 & 1 & 56.9 \\
\hline 29 & -1 & 1 & 1 & 1 & 54.9 \\
\hline 30 & 1 & -1 & -1 & 1 & 61.2 \\
\hline
\end{tabular}

chloride to compound III $(3.1: 1)$, reaction time $(4 \mathrm{~h})$, reaction temperature $\left(40^{\circ} \mathrm{C}\right)$, and the pyridine loading $(1.5 \mathrm{~g})$. Finally, we performed five parallel experiments under the optimized reaction conditions, and compound IV was obtained in $74.3 \%, 72.5 \%, 73.1 \%, 73.5 \%$, and $72.0 \%$ yields, respectively, with the purity reaching to $99 \%$. The average yield was $73.1 \%$ with a deviation of $0.66 \%$. 


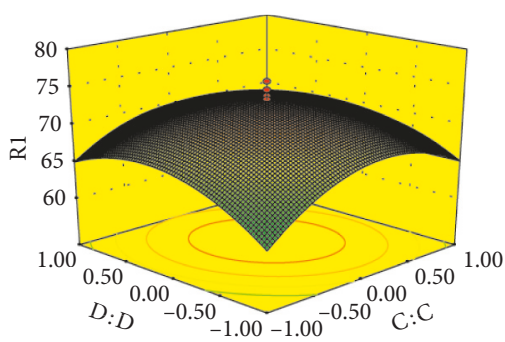

(a)

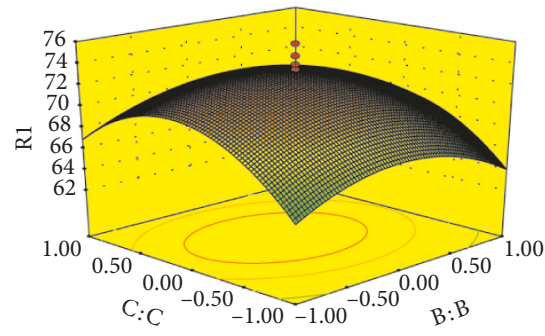

(c)

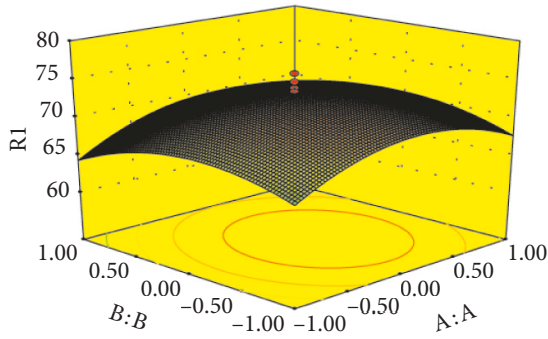

(e)

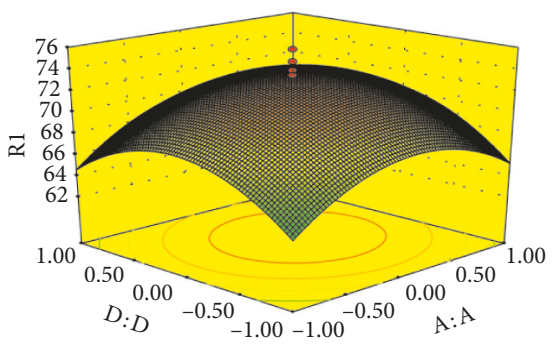

(b)

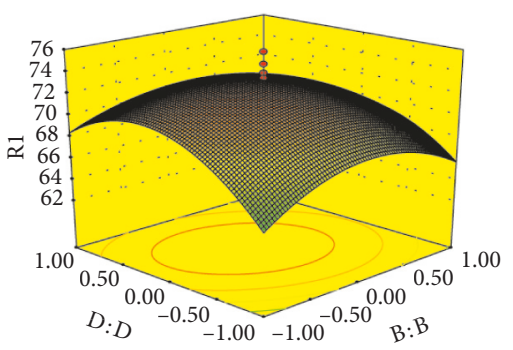

(d)

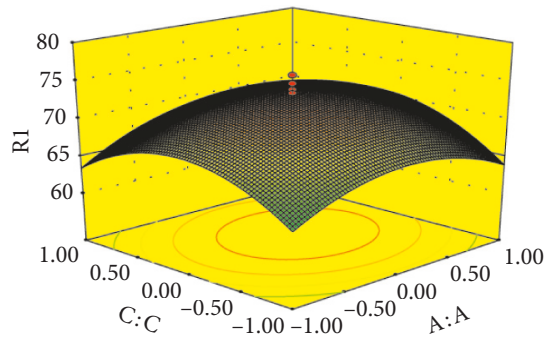

(f)

Figure 11: The response surface of product IV.

As for the oxidation step, Cheng et al. [22] reported a method that treated 1-acetyladamantane with potassium permanganate in pyridine to get the target compound; however, pyridine is poisonous. So, we used nontoxic t-butanol instead of pyridine. In addition, considering that 1 -acetyladamantane and potassium permanganate are not easily soluble in $t$-butanol, the phase transfer catalyst (PTC) was added to improve the two-phase reaction system $[23,24]$. The types of PTC were also examined; we fixed the mole ratio of PTC to compound IV to $1: 20$, reaction time to $2.5 \mathrm{~h}$, reaction temperature to $40^{\circ} \mathrm{C}$, and the mole ratio of potassium permanganate to compound IV to $1.5: 1$, to investigate the influence of PTC species on the yields (Table 3 ).

As shown in Table 3, the addition of phase transfer catalyst can improve the reaction yield obviously. TBAB was a good choice which raised the yield to $91 \%$; therefore, TBAB was added to the reaction solution to shorten the reaction time and improve the yield.

\section{Experimental}

All reagents were purchased commercially and were used as supplied unless otherwise specified. Melting points were determined through SGW X-4 micromelting point apparatus. IR was recorded using a Nicolet FTIR 5700 spectrophotometer, ESI-MS spectra were recorded from a
TABLE 3: Impact of the phase transfer catalyst on yield.

\begin{tabular}{lc}
\hline Phase transfer catalyst & The yield of compound I (\%) \\
\hline- & 70 \\
PEG-400 & 81 \\
TEBAC & 89 \\
TBAB & 91 \\
\hline
\end{tabular}

Finnigan LCQ Advantage Max spectrometer, and ${ }^{1} \mathrm{H}-\mathrm{NMR}$ was recorded on a Bruker Avance III $600 \mathrm{MHz}$ spectrometer.

3.1. Preparation of 3-Hydroxy-1-adamantanecarboxylic Acid (III). A $150 \mathrm{~mL}$ three-necked round bottom flask was equipped with magnetic stirrer and thermometer. The flask was charged with sulfuric acid $(98 \%, 20 \mathrm{~mL})$ and nitric acid $(65 \%, 2 \mathrm{~mL})$ in turn. The mixed acid was stirred at $0^{\circ} \mathrm{C}$ for $1 \mathrm{~h}$, followed by addition of 1-adamantanecarboxylic acid $(5.0 \mathrm{~g}, 0.028 \mathrm{~mol})$ in portions within $0.5 \mathrm{~h}$ while maintaining the temperature at $0^{\circ} \mathrm{C}$. Thereafter, the reaction mixture was stirred at room temperature for $12 \mathrm{hrs}$. Water $(125 \mathrm{~mL})$ was added to the reaction mixture and stirred for $5 \mathrm{hrs}$. Then, the suspension was filtered, and the filter cake was recrystallized with propanone/water and dried over $\mathrm{Na}_{2} \mathrm{SO}_{4}$ to afford purified compound III (4.90 g, 90.0\% yield). M.p. 199 200 ${ }^{\circ} \mathrm{C}$ 
(lit. [18] 199 200 $\left.{ }^{\circ} \mathrm{C}\right)$; IR ( $\left.\mathrm{KBr}, \mathrm{cm}^{-1}\right)$ : 3460, 2850, 1680, 1200, 1100,$600 ;{ }^{1} \mathrm{H}$ NMR (600 MHz, DMSO-d6) $\delta: 11.89$ (br s, $1 \mathrm{H}$, $\mathrm{COOH}), 4.50$ (br s, $1 \mathrm{H}, \mathrm{OH}), 2.12 \sim 2.14(\mathrm{~m}, 2 \mathrm{H}, \mathrm{CH})$, 1.66 1.48 (m, 12H, CH $\left.{ }_{2}\right)$; ESI-MS $(\mathrm{m} / \mathrm{z}): 197(\mathrm{M}+1)^{+}$.

3.2. Preparation of 3-Hydroxy-1-acetyladamantane (IV). A mixture of pyridine $(4.5 \mathrm{~mL}, 0.056 \mathrm{~mol})$ and compound III ( $5.5 \mathrm{~g}, 0.028 \mathrm{~mol})$ was stirred in an ice-water bath for an hour; then, acetyl chloride $(10 \mathrm{~mL}, 0.138 \mathrm{~mol})$ was added dropwise to the mixture, and this solution was stirred at $25^{\circ} \mathrm{C}$ for $3 \mathrm{~h}$. After that, pyridine hydrochloride was formed and was filtered. The excess acetyl chloride of filtrate was removed with reduced pressure, and the residue was 3hydroxy-1-adamantyl methacetic anhydride. A mixture of diethyl malonate $(7.4 \mathrm{~mL}, 0.042 \mathrm{~mol})$ and petroleum ether $(20 \mathrm{ml})$ were added dropwise to metallic sodium in petroleum ether $(100 \mathrm{~mL})$. The mixture was stirred for another $15 \mathrm{~h}$ at room temperature to get white precipitates. Afterwards, previously prepared 3-hydroxy-1-adamantyl methacetic anhydride in petroleum ether $(20 \mathrm{~mL})$ was added to the preceding suspension slowly; then, the mixture was stirred at room temperature for $12 \mathrm{~h}$. Afterwards, water $(50 \mathrm{ml})$ was added to the solution and stirred for about 10 minutes, and the organic layers were separated and concentrated with reduced pressure to give the oil residue. After that, a mixed solution of acetic acid $(20 \mathrm{ml})$, water $(6 \mathrm{ml})$, and sulfuric acid $(2 \mathrm{~mL})$ was added to the residue obtained as above, the reaction mixture was then refluxed for $8 \mathrm{~h}$ and then poured into cold water $(200 \mathrm{~mL})$, which was extracted with ethyl acetate $(3 \times 10 \mathrm{~mL})$, and the combined organic layers were washed with water $(100 \mathrm{~mL})$, dried over $\mathrm{Na}_{2} \mathrm{SO}_{4}$, and concentrated under reduced pressure. The residue was recrystallized from methylene chloride/hexane to give compound IV (3.69g, 74.6\% yield).M.p. $89 \sim 90^{\circ} \mathrm{C}\left(\right.$ lit. [25] 89 90 $\left.{ }^{\circ} \mathrm{C}\right)$; IR (KBr, cm-1): $3380,2880,2850,1750,1410,1000,600 ; 1 \mathrm{H}$ NMR (600 MHz, DMSO-d6) $\delta: 4.52$ (s, 1H, OH), 2.22 (br s, 2H, $\mathrm{CH}), 2.05$ (s, 3H, CH3), 1.62 1.47 (m, 12H, CH2); ESI-MS $(\mathrm{m} / \mathrm{z}): 195(\mathrm{M}+1)+$.

3.3. Preparation of 2-(3-Hydroxy-1-adamantyl)-2-Oxoacetic Acid (I). The tert-butanol $(10 \mathrm{~mL}), 2 \% \mathrm{KOH}(100 \mathrm{~mL})$, compound IV ( $5.0 \mathrm{~g}, 0.026 \mathrm{~mol})$, and phase transfer catalyst TBAB were added to a $250 \mathrm{~mL}$ three-necked flask; then, the mixture was stirred at $40^{\circ} \mathrm{C}$, and potassium permanganate $(8.3 \mathrm{~g}, 0.052 \mathrm{~mol})$ was added in batches during a period of $1 \mathrm{~h}$. After that, the solution was stirred for $5 \mathrm{~h}$; then, sodium sulfite $(3.8 \mathrm{~g}, 0.026 \mathrm{~mol})$ was added and stirred for $10 \mathrm{~min}$, and the mixture was filtered. The filtrate was adjusted to $\mathrm{pH}$ 1-2 and then extracted with ethyl acetate $(10 \mathrm{~mL} \times 3)$, and the organic phases were combined, which was concentrated under reduced pressure to get a light yellow oil residue. The residue was recrystallized by heptane and dried to obtain compound I (5.3 g, 91.8\% yield). M.p. $163-165^{\circ} \mathrm{C}$ (lit. [26] $\left.164 \sim 165^{\circ} \mathrm{C}\right)$; IR $\left(\mathrm{KBr}, \mathrm{cm}^{-1}\right): 3380,2920,2850,1713,1680$; ${ }^{1} \mathrm{H}$ NMR (600 MHz, DMSO-d6) $\delta: 14.2$ (br s, $\left.1 \mathrm{H}, \mathrm{COOH}\right)$, 4.6 (br s, $1 \mathrm{H}, \mathrm{OH}), 2.19$ (s, 2H, CH) $1.72-1.46(\mathrm{~m}, 12 \mathrm{H}$, $\left.\mathrm{CH}_{2}\right)$; $\operatorname{ESI}-\mathrm{MS}(\mathrm{m} / \mathrm{z}): 225(\mathrm{M}+1)^{+}$.

\section{Conclusion}

This study provides a simple and economical method to synthesis 2-(3-hydroxy-1-adamantane)-2-oxoacetic acid in $60 \%$ yield from 1-adamantanecarboxylic acid over five steps. The reaction is mild, simple, and inexpensive, which represents a great improvement compared with previously reported methods and has a great foreground of development.

\section{Data Availability}

The figure and table data used to support the findings of this study are included within the article.

\section{Conflicts of Interest}

The authors declare that there are no conflicts of interest regarding the publication of this paper.

\section{Authors' Contributions}

Qi Liao and Lan Jiang have contributed equally to this work.

\section{Acknowledgments}

The authors are deeply grateful for the support of the Chongqing Science and Technology Commission (cstc2015zdcy-ztzx120003) for this study. The authors also appreciate that the Undergraduate Innovative Experiment Program of Chongqing Medical University (no. 201971) for providing financial aid for our work.

\section{References}

[1] N. H. Cho, J. E. Shaw, S. Karuranga et al., "IDF diabetes atlas: global estimates of diabetes prevalence for 2017 and projections for 2045," Diabetes Research and Clinical Practice, vol. 138, pp. 271-281, 2018.

[2] M. Long, L. Cai, W. Li et al., "DPP-4 inhibitors improve diabetic wound healing via direct and indirect promotion of epithelial-mesenchymal transition and reduction of scarring," Diabetes, vol. 67, no. 3, pp. 518-531, 2018.

[3] A. J. Scheen, "Safety of dipeptidyl peptidase-4 inhibitors for treating type 2 diabetes," Expert Opinion on Drug Safety, vol. 14, no. 4, pp. 505-524, 2015.

[4] J. Geng, H. Yu, Y. Mao, P. Zhang, and Y. Chen, "Cost effectiveness of dipeptidyl peptidase- 4 inhibitors for type 2 diabetes," Pharmacoeconomics, vol. 33, no. 6, pp. 581-597, 2015.

[5] S. Dhillon, "Saxagliptin: a review in type 2 diabetes," Drugs, vol. 75, no. 15, pp. 1783-1796, 2015.

[6] G. Mospan, C. Mospan, S. Vance, A. Bradshaw, K. Meosky, and K. Bowles, "Drug updates and approvals," The Nurse Practitioner, vol. 42, no. 12, pp. 8-16, 2017.

[7] S. A. Savage, G. S. Jones, S. Kolotuchin, S. A. Ramrattan, T. Vu, and R. E. Waltermire, "Preparation of saxagliptin, a novel DPP-IV inhibitor," Organic Process Research \& Development, vol. 13, no. 6, pp. 1169-1176, 2009.

[8] C. V. Truc, D. B. Brzozowski, R. Fox et al., "Methods and compounds for producing dipeptidyl peptidase IV inhibitors and intermediates," EP 2792672A3, 2005. 
[9] L. H. Ronald, L. G. Steven, B. B. David et al., "Preparation of an amino acid intermediate for the dipeptidyl peptidase IV inhibitor, saxagliptin, using a modified phenylalanine dehydrogenase," Advanced Synthesis \& Catalysis, vol. 349, no. 89, pp. 1369-1378, 2010.

[10] M. Politino, M. M. Cadin, P. M. Skonezny et al., "Process for preparing dipeptidyl IV inhibitors and intermediates," EP 1737970, 2005.

[11] V. Henryon, J. Monbrun, and M. Casado, "Method for producing adamantyl compounds: WO," WO/2010/032129, 2010.

[12] J. Li, S. Zhang, H. Zhou, J. Peng, Y. Feng, and X. Hu, "Preparation of 2-(3-hydroxy-1-adamantyl)-2-oxoacetic acid: a key intermediate for saxagliptin," Letters in Organic Chemistry, vol. 9, no. 5, pp. 347-350, 2012.

[13] M. Berner, R. Partanen, A. Salakka et al., "Process for the preparation of adamantane derivatives," US Patent 7205432, 2007.

[14] T. Wilhelm, K. Knepper, W. Felzmann et al., "Process for the reductive amination of $\alpha$-keto carboxylic acids," WO/2012/ 028721, 2012.

[15] R. Venkat, M. Raghu, K. Ajay et al., "A process for industrial preparation of [(S)-N-tert butoxycarbonyl-3-hydroxy] adamantyl glycine," WO 2014057495, 2014.

[16] G. Bertolini, M. Sada, S. Maiorana et al., "Process for the preparation of intermediates of synthesis of saxagliptin and novel compounds," WO2014/118612, 2014.

[17] R. Gan, M. Zhang, J. Li et al., "Synthesis of 2-(3-hydroxy-1adamantyl)-2-oxoacetic acid," Chinese Journal of Pharmaceuticals, vol. 47, no. 10, pp. 131-133, 2016.

[18] J. Li, X. Jiang, R. Gan et al., "A facile and economic method for the synthesis of (S)-N-Boc-3'-hydroxyadamantylglycine," Research on Chemical Intermediates, vol. 42, no. 6, pp. 1-13, 2016.

[19] M. Basri, M. A. Alrub, E. A. Malek, S. Ainliah, A. B. Salleh, and M. B. Abdul Rahman, "Optimization of lipase-catalyzed synthesis OFN-trans-feruloyltyramine using response surface methodology (RSM)," Chemical Engineering Communications, vol. 201, no. 12, pp. 1582-1592, 2014.

[20] Y. Feng, Y. J. Cheng, J. Peng et al., "Optimization of the synthesis process of 2-(3-hydroxy-1-adamantyl)-2-oxoacetic acid by the central composite design-response surface methodology," Chemical Research \& Application, vol. 25, no. 2, pp. 194-199, 2013.

[21] S. L. C. Ferreira, R. E. Bruns, E. G. P. da Silva et al., "Statistical designs and response surface techniques for the optimization of chromatographic systems," Journal of Chromatography A, vol. 1158, no. 1-2, pp. 2-14, 2007.

[22] W.-M. Cheng, R. Shang, H.-Z. Yu, and Y. Fu, "Room-temperature decarboxylative couplings of $\alpha$-oxocarboxylates with aryl halides by merging photoredox with palladium catalysis," Chemistry - A European Journal, vol. 21, no. 38, pp. 1319113195, 2015.

[23] Q. W. Wang, Y. Y. Wei, and C. B. Yue, "Preparation of 3methyl-4-nitrobenzoic acid via oxidation of 2,4-dimethylnitrobenzene in presence of phase transfer catalyst," Speciality Petrochemicals, vol. 24, no. 1, pp. 26-29, 2007.

[24] N. Zhang, J. Xie, and V. K. Varadan, "Functionalization of carbon nanotubes by potassium permanganate assisted with phase transfer catalyst," Smart Materials and Structures, vol. 11, no. 6, pp. 962-965, 2002.

[25] R. Gan, J. Zhou, J. Li, M. Zhang, X. Jiang, and X. Hu, “An improved synthetic method of saxagliptin intermediate 3- hydroxy-1- acetyladamantane and its characterization," Letters in Organic Chemistry, vol. 13, no. 7, pp. 514-518, 2016.

[26] F. Liu, W. Yu, J. Zhang et al., "A novel method for the synthesis of 2-(3-hydroxy-1-adamantyl)-2-oxoacetic acid," Journal of Chemical Research, vol. 37, no. 12, pp. 722-723, 2013. 

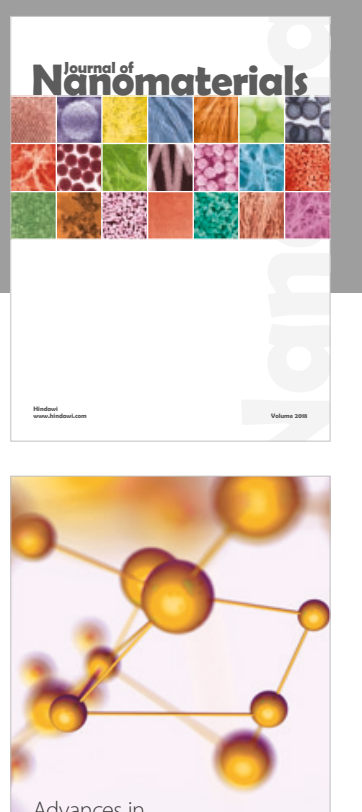

Physical Chemistry
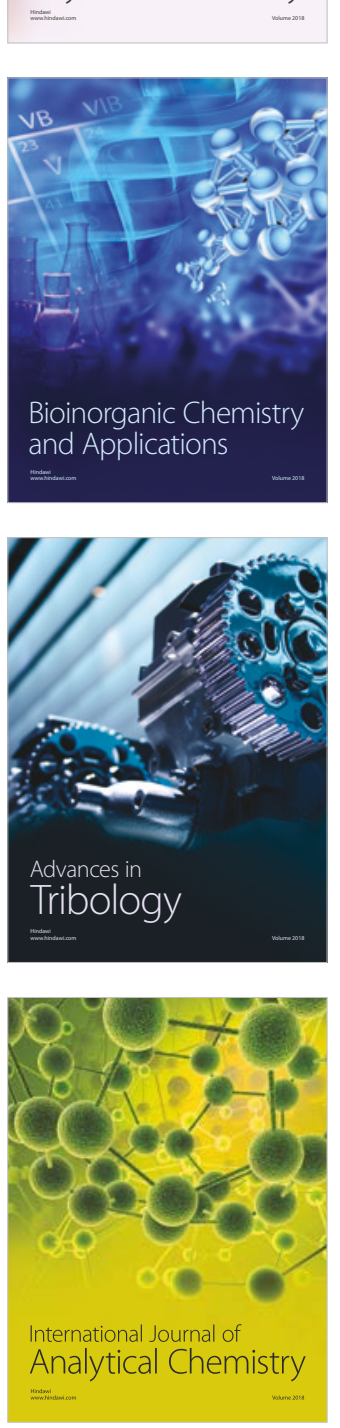

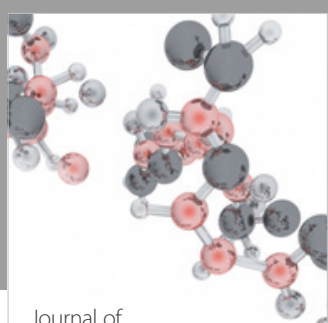

Analytical Methods

in Chemistry

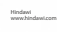

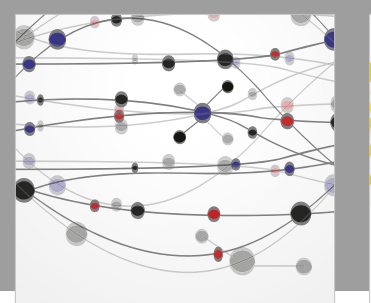

The Scientific World Journal

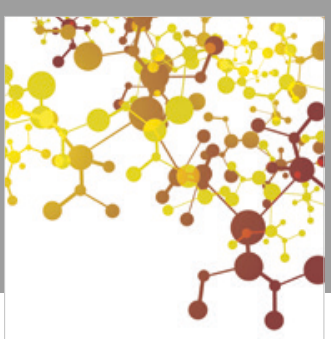

Journal of

Applied Chemistry
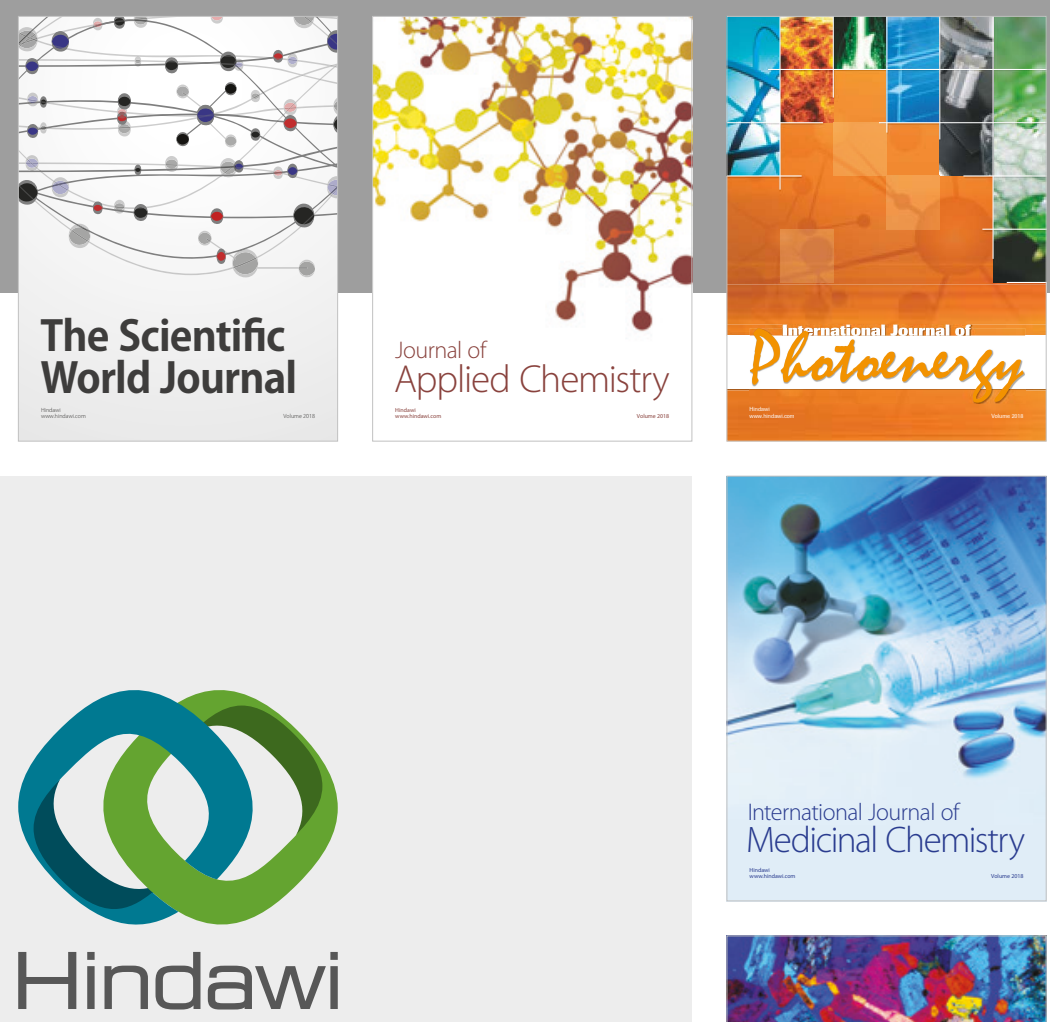

Submit your manuscripts at

www.hindawi.com
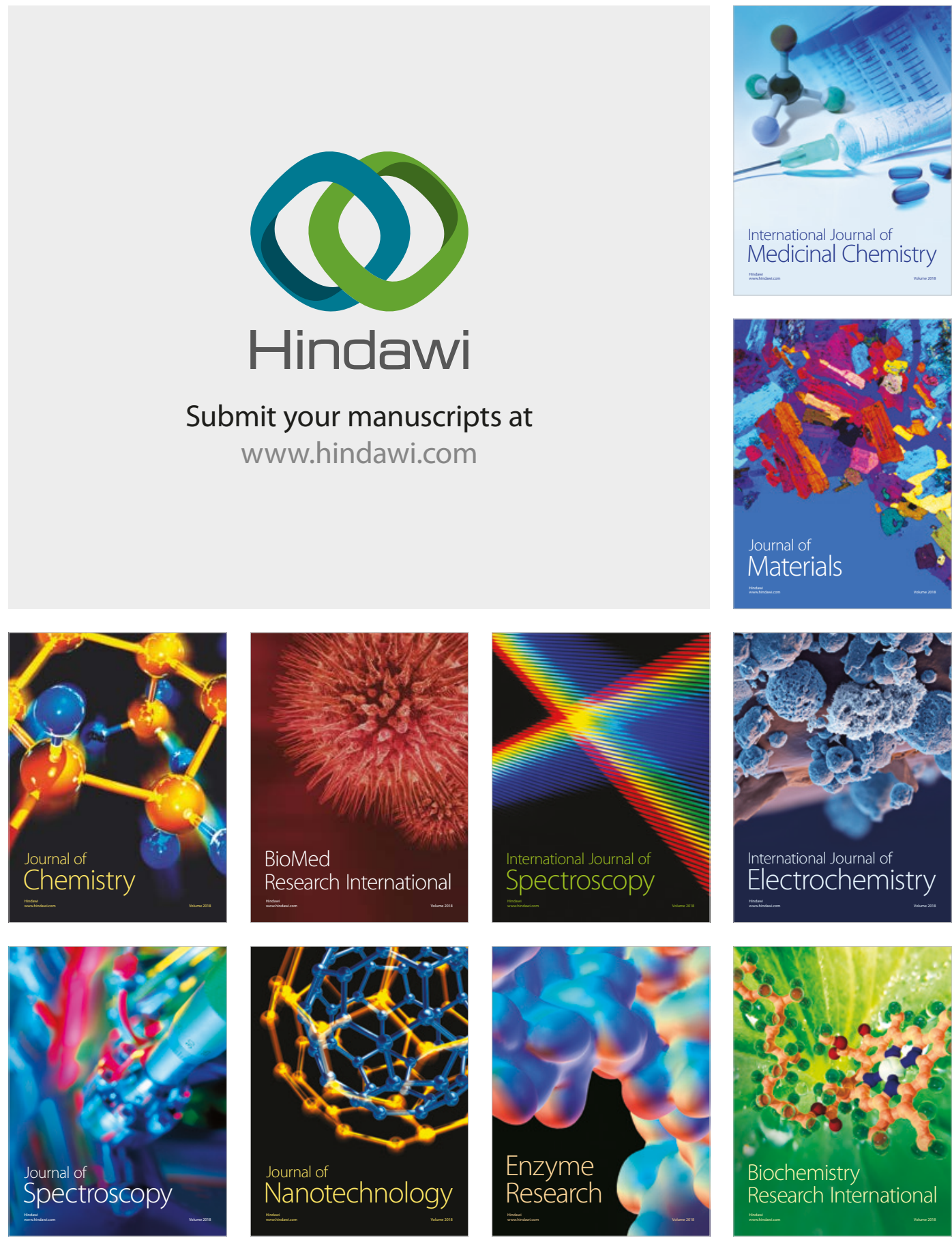
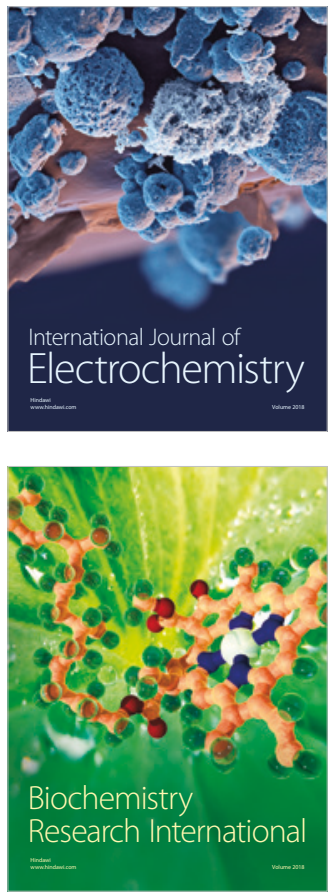